\title{
Inhibition of Brain Epidermal Growth Factor Receptor Activation: A Novel Target in Neurodegenerative Diseases and Brain Injuries
}

\author{
Omid Tavassoly, Takashi Sato, and Iman Tavassoly \\ Department of Chemistry, Simon Fraser University, Burnaby, British Columbia, Canada (O.T.); Division of Pulmonary \\ Medicine, Department of Medicine, Keio University School of Medicine, Shinjuku-ku, Tokyo, Japan (T.S.); Division of \\ Pulmonary Medicine, Department of Medicine, Keiyu Hospital, Yokohama-shi, Kanagawa, Japan (T.S.); and Mount Sinai \\ Institute for Systems Biomedicine, Icahn School of Medicine at Mount Sinai, New York, New York (I.T.)
}

Received March 2, 2020; accepted April 10, 2020

\begin{abstract}
Several reports have been published recently demonstrating a beneficial effect of epidermal growth factor receptor (EGFR) inhibitors in improving pathologic and behavioral conditions in neurodegenerative diseases (NDDs) such as Alzheimer's disease and Amyotrophic Lateral Sclerosis (ALS) as well as the brain and spinal cord injuries (SCl). Despite successful therapeutic effects of EGFR inhibition in these pathologic conditions, there is still no report of proof-of-concept studies in well-characterized animal models using recently developed blood-brain barrier (BBB)-penetrating EGFR inhibitors, which is due to previous conflicting reports concerning the level of EGFR or activated EGFR in normal and pathologic conditions that caused target engagement to be a concern in any future EGFR inhibition therapy. In this review, the level of EGFR expression and activation in the developing central nervous system (CNS) compared with the adult CNS will be explained as well as how neuronal injury or pathologic conditions, especially inflammation
\end{abstract}

and amyloid fibrils, induce reactive astrocytes leading to an increase in the expression and activation of EGFR and, finally, neurodegeneration. Furthermore, in this review, we will discuss two main molecular mechanisms that can be proposed as the neuroprotective effects of EGFR inhibition in these pathologic conditions. We will also review the recent advances in the development of BBB-penetrating EGFR inhibitors in cancer therapy, which may eventually be repositioned for NDDs and $\mathrm{SCl}$ therapy in the future.

\section{SIGNIFICANCE STATEMENT}

Based on the lessons from the applications of EGFR inhibitors in oncology, it is concluded that EGFR inhibitors can be beneficial in treatment of neurodegenerative diseases and spinal cord injuries. They carry their therapeutic potentials through induction of autophagy and attenuation of reactive astrocytes.

\section{Introduction}

Several reports have been published in the last 10 years demonstrating beneficial effect of epidermal growth factor receptor (EGFR) inhibitors in improving pathologic and behavioral conditions in neurodegenerative diseases (NDDs) such as Alzheimer's Disease (AD) (Wang et al., 2012a, 2013, 2017) and Amyotrophic Lateral Sclerosis (ALS) (Le Pichon et al., 2013) as well as brain and Spinal Cord Injuries (SCI) (Erschbamer et al., 2007; Li et al., 2011, 2014; Yang et al., 2011; Qu et al., 2012; Kjell et al., 2014; Zhang et al., 2016).

O.T. is supported by a grant from the W. Garfield Weston Foundation (Weston Brain Institute) [RR171033].

https://doi.org/10.1124/mol.120.119909.
EGFR inhibitors are mainly designed to inhibit mutants of EGFR or excess EGFR activation in cancer and tumor tissues (Sigismund et al., 2018; Roskoski, 2019). In cancer, it has been known that oncogenic EGFR mutation, amplification, or overexpression leads to the excessive activation of EGFR protein, causing uncontrolled proliferation. Mutations in the EGFR gene are mutually exclusive with the other driver genetic alterations such as Kirsten Rat Sarcoma Viral Oncogene Homolog mutations. In non-small cell lung cancer (NSCLC), to be positive for EGFR mutation determines if a patient is a candidate for treatment with the EGFR inhibitors (Schilsky, 2010; Tavassoly et al., 2019). Of note, in addition to the fact that EGFR plays an oncogenic role in many cancers, EGFR signaling is also associated with aberrant

ABBREVIATIONS: AD, Alzheimer's disease; ALS, Amyotrophic Lateral Sclerosis; BBB, blood-brain barrier; CNS, central nervous system; CRMP2, collapsin response mediator protein-2; CSPG, chondroitin sulfate proteoglycan; EGFR, epidermal growth factor receptor; GFAP, glial fibrillary acidic protein; GSK3 $\beta$, synthase kinase-3 $\beta$; HER1, human epidermal growth factor receptor 1; IL, interleukin; mTOR, mammalian target of rapamycin; NDDs, neurodegenerative diseases; NPC, neural progenitor cell; NSC, neural stem cell; NSCLC, non-small cell lung cancer; OGD, oxygen/glucose deprivation; p-EGFR, phosphorylated epidermal growth factor receptor; PI3K, phosphoinositide 3-kinase; PS1, presenilin-1; SCI, spinal cord injuries; SNP, single nucleotide polymorphism; TNF- $\alpha$, tumor necrosis factor; WB, Western blot; ZNRF1, zinc and ring finger-1. 
cellular differentiation in cancer (Kolev et al., 2008; Sato et al., 2019), which may be targeted by EGFR inhibitors similarly as that in NDDs and SCI. Although there are polymorphisms in EGFR genes that are associated with $\mathrm{AD}$ (Chen et al., 2018), there is no report of an association between known cancerrelated EGFR mutations and the development of $\mathrm{AD}$ and other neurodegenerative diseases. Furthermore, there have been conflicting reports concerning the level of EGFR in NDDs. It would appear that in some cases, total EGFR level is reported to be reduced (Iwakura et al., 2005; Wang et al., 2013), and in other cases, it is reported to be increased (Birecree et al., 1988; Styren et al., 1993; Liu et al., 2006) or unchanged (Wang et al., 2017). Therefore, repositioning of EGFR inhibitor drugs for the treatment of NDDs and SCI requires a better understanding of their molecular mechanism in NDDs and SCI as well as proof-of-target engagement in both in vitro and preclinical animal models. In this paper, we will emphasize that the ratio of phosphorylated EGFR (p-EGFR) to EGFR (p-EGFR/EGFR), called "activated EGFR" in this paper, is to be considered a biologic marker of pathology, as it has been shown in studies of cancer and AD (Noro et al., 2006; Hammoud et al., 2009; Wang et al., 2012a, 2013, 2016; Dhaunsi et al., 2016; Overmiller et al., 2016). Furthermore, a common pathologic feature in both NDDs and SCI is reactive astrocytes, which are characterized as high-expressed EGFR astrocytes with high levels of activated EGFR (Liu and Neufeld, 2004; Zhang and Neufeld, 2005; Liu et al., 2006; Liu and Neufeld, 2007; Chen et al., 2017). Stimulations such as injuries, genetic mutations in familial NDDs (Booth et al., 2017; Frost and Li, 2017; González-Reyes et al., 2017; Ceyzériat et al., 2018; Joe et al., 2018; Perez-Nievas and Serrano-Pozo, 2018), and amyloid fibrils (Forman et al., 2005; Kahlson and Colodner, 2015; Chavarría et al., 2018; Diniz et al., 2019; Lohmann et al., 2019; Tremblay et al., 2019) can induce a reactive astrocytes condition, which finally leads to neurodegeneration. Considering the beneficial effect of EGFR inhibition in neurodegenerative diseases and treatment of reactive astrocytes pathology in SCI, there is an essential need to clarify the role of EGFR activation in noncancer brain pathologies as well as molecular pharmacology of EGFR inhibition as a novel therapy for both NDDs and SCI. In this paper, we review the literature and discuss possible molecular mechanisms for the therapeutic effect of EGFR inhibition in NDDs and SCI in comparison with its role in cancer, including 1) Autophagy Induction and 2) Attenuation of Reactive Astrocytes Pathology. One of the main modes of action of EGFR inhibitors in cancer therapy is to induce autophagy (Han, 2011; Tyson et al., 2011; Fung, 2012), which is also reported in AD (Wang et al., 2017). Moreover, EGFR expression is upregulated in reactive astrocytes, and its hyperactivation leads to astrogliosis (Li et al., 2011, 2014; Chen et al., 2017). Another issue regarding the use of EGFR inhibitors as a therapy in NDDs and SCI is that most of the previous reports involve two of the classic EGFR inhibitors (gefitinib and erlotinib) (Yang et al., 2011; Wang et al., 2012a, 2013, 2017; Le Pichon et al., 2013; Kjell et al., 2014; Zhang et al., 2016). These drugs were designed for peripheral tumors and do not display sufficient brain penetration (Erschbamer et al., 2007; Kim et al., 2019). Thus, they are not suitable for the proof-of-concept studies in NDDs and SCI. In this paper, we will also review the recent advances in the development of blood-brain barrier (BBB)-penetrating EGFR inhibitors in cancer therapy, which may eventually be repositioned for NDD and SCI therapy in the future.

\section{EGFR Structure and Function}

EGFR, also called HER1 or EebB-1, is a member of Human Epidermal Growth Factor Receptor 1 (HER) or ErbB family of tyrosine kinase receptors. It has a single transmembrane domain, an extracellular domain that binds to specific ligands, and the intracellular domain, which undergoes autophosphorylation at tyrosine residues upon activation (Carpenter and Cohen, 1990; Yarden, 2001; Herbst, 2004; Avraham and Yarden, 2011). Binding of EGFR ligands to the extracellular domain leads to homodimerization or heterodimerization with the other ErbB family members and autophosphorylation of the C-terminal domain, which activates a cascade of downstream phosphorylation to control cellular differentiation and proliferation. EGFR has seven ligands, including Epidermal Growth Factor (EGF), transforming growth factor- $\alpha$, heparinbinding EGF-like growth factor, betacellulin, amphiregulin, epiregulin, and epigen (Schreiber et al., 1986; Toyoda et al., 1995; Raab and Klagsbrun, 1997; Dunbar and Goddard, 2000; Vecchione et al., 2011; Berasain and Avila, 2014; Schneider and Yarden, 2014).

\section{EGFR Expression Level and Its Role in Developing an Adult Brain}

EGFR has an essential role in cellular differentiation in developing brain, which includes differentiation of both neurons (neurogenesis) and glial cells (gliogenesis; generation of glial cells, including astrocytes, oligodendrocytes, Schwann cells, and microglia, during development) from neural stem cells (NSC), neural progenitor cells (NPC), and glial progenitor cells. There is an increase in the expression and activation of EGFR during the neurogenesis and gliogenesis, especially in NSCs, NPCs, and glial progenitor cells of germinal zones (Enwere et al., 2004; Galvez-Contreras et al., 2013; Lupo et al., 2019). During embryonic development, EGFR expression starts as early as E11-E13 (11-13-day-old rat embryo) in the midbrain (germinal zone, rostral, and pretectum) in the rat. The EGFR expression starts in the diencephalon (ventral thalamus, dorsal hypothalamus, and hypothalamic germinal zone) and cerebellum (external granule cell layer and fourth ventricular germinal zone) at E15 of embryonic development. Forebrain EGFR expression starts at E17 in basal ganglia germinal zone and neostriatum (caudate-putamen). During the perinatal period, the level of EGFR expression increases progressively, and at 1 day after birth, almost all brain regions express EGFR. In the substantia nigra of midbrain, tyrosine hydroxylase expressing dopaminergic neurons also express EGFR during the perinatal period (Kaser et al., 1992; Seroogy et al., 1995; Kornblum et al., 1997). The EGFR expression and activation are essential for the development of astrocytes and neurons in the developing central nervous system (CNS), but upon differentiation in the adult CNS, EGFR expression in these cells will be reduced, and its activation is absent in adult brain (Enwere et al., 2004; Galvez-Contreras et al., 2013; Lupo et al., 2019). Astrocytes in the adult brain will stay as quiescent astrocytes, but following neuronal injuries or pathologic conditions, EGFR upregulates and quiescent astrocytes are transformed to reactive astrocytes (Enwere et al., 2004; Liu et al., 2006; Liu and Neufeld, 2007; Galvez-Contreras et al., 2013; Chen et al., 2017; Lupo et al., 2019). In the adult brain, the high levels of EGFR expression are limited to NSCs 
and NPCs of subventricular zone, but EGFR expression is detected in neurons at basal levels through life. The expression level of EGFR in astrocytes becomes barely detectable or absent 2 to 3 months after birth (Enwere et al., 2004; Galvez-Contreras et al., 2013, Lupo et al., 2019).

Mounting evidence now suggests an increase in the level of activated EGFR ( $p$-EGFR/EGFR) in the adult brains of neurodegenerative diseases, such as AD, Parkinson's disease, and ALS, as well as brain and spinal cord injuries. This activation and upregulation of EGFR are reported in both reactive astrocytes and neurons (Liu and Neufeld, 2004; Zhang and Neufeld, 2005; Liu et al., 2006; Erschbamer et al., 2007; Li et al., 2011, 2014; Yang et al., 2011; Qu et al., 2012; Wang et al., 2012a, 2013; Kjell et al., 2014; Wakatsuki et al., 2015; Wakatsuki and Araki, 2016; Zhang et al., 2016; Chen et al., 2017).

\section{EGFR Activation in the Pathologic Adult Brain Leads to Induction of Reactive Astrocytes}

In the adult brain, injuries and pathologic conditions activate EGFR in both neurons and astrocytes (Liu and Neufeld, 2004; Zhang and Neufeld, 2005; Liu et al., 2006; Wakatsuki et al., 2015; Wakatsuki and Araki, 2016; Chen et al., 2017). This includes Huntington disease (Gu et al., 2005; Faideau et al., 2010; Abjean et al., 2018), AD (Jo et al., 2014; Ceyzériat et al., 2018), Parkinson's disease (Bandopadhyay et al., 2004; Neumann et al., 2004; Koprich et al., 2008), ALS (Kushner et al., 1991; Tripathi et al., 2017), amyloid structure formation such as $\alpha$-synuclein (Chavarría et al., 2018; Duffy et al., 2018) and $\beta$-amyloid (Pike et al., 1994; Söllvander et al., 2016), and traumatic brain injuries such as weight-drop technique (Erschbamer et al., 2007; Li et al., 2011, 2014; Qu et al., 2012; Kjell et al., 2014; Shandra et al., 2019), oxygen/glucose deprivation (OGD) (Wang et al., 2012b; Liu et al., 2019), and ischemic injury (Morizawa et al., 2017; Laug et al., 2019). In all these conditions, there is an increase in the level of EGFR expression and activated EGFR (p-EGFR/EGFR) in the brain and spinal cord associated with a raise in the level of glial fibrillary acidic protein (GFAP), which is a marker of reactive astrocytes (Liu and Neufeld, 2004; Zhang and Neufeld, 2005; Liu, 2006; Erschbamer et al., 2007; Li et al., 2011, 2014; Yang et al., 2011; Qu et al., 2012; Kjell et al., 2014; Zhang et al., 2016; Chen et al., 2017). Under normal conditions, with no injury or pathology, astrocytes exist as quiescent astrocytes with barely detectable levels of EGFR. Quiescent astrocytes are required for neuronal survival, and the loss of normal astrocyte function in reactive astrocytes is associated with the pathology of neurodegenerative diseases (Liu and Neufeld, 2004; Zhang and Neufeld, 2005; Liu et al., 2006; Erschbamer et al., 2007; Li et al., 2011, 2014; Yang et al., 2011; Qu et al., 2012; Kjell et al., 2014; Zhang et al., 2016; Chen et al., 2017) (Fig. 1). Besides the indirect effect of EGFR activation in reactive astrocytes on neuronal degeneration, it has been reported that oxidative stress can directly activate EGFR in neuronal cells and finally lead to degeneration and apoptosis in neurons (Wakatsuki et al., 2015; Wakatsuki and Araki, 2016). Oxidative stress induced by treatment of neuronal cells with 6-hydroxydopamine or $\mathrm{H}_{2} \mathrm{O}_{2}$ as well as in vivo by traumatic injury induction in animals, which causes the generation of NADPH oxidases in axons, stimulates neuronal EGFR tyrosine kinase activity. Activated EGFR phosphorylates zinc and ring finger-1 (ZNRF1) at Y103 and subsequently activates the E3 ubiquitin ligase activity of ZNRF1. Activated ZNRF1 ubiquitinates AKT to be degraded by ubiquitin/proteasome system. Reduction in the level of active AKT rescues the inhibitory phosphorylation of glycogen synthase kinase-3 $\beta$ (GSK3 $\beta$ ) by AKT and subsequently activates GSK3 $\beta$ which leads to phosphorylation of collapsin response mediator protein-2 (CRMP2). CRMP2 is required for microtubule stabilization in axons, but phosphorylation of CRMP2 by GSK3 $\beta$ inactivates CRMP2 and finally

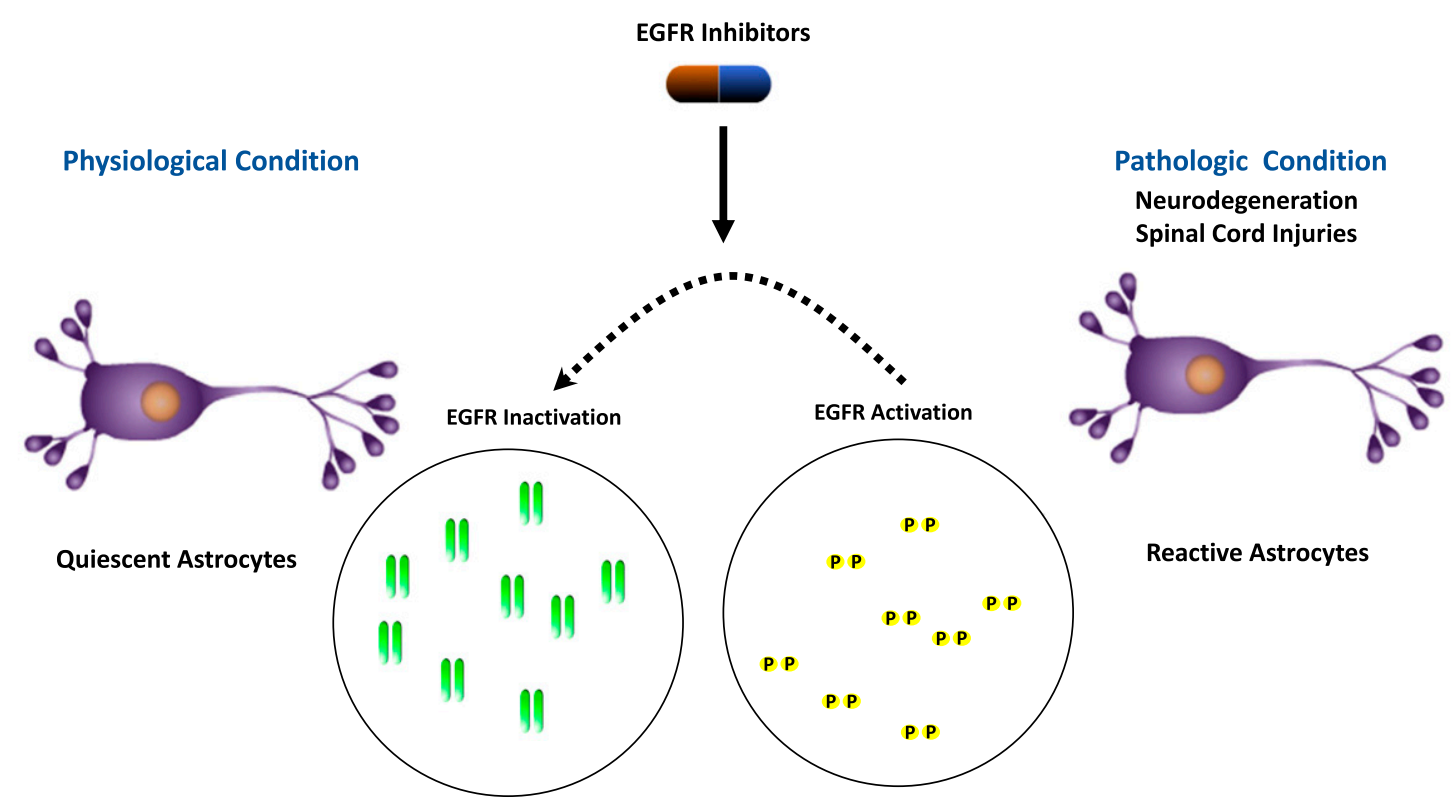

Fig. 1. Under normal conditions, with no injury or pathology, astrocytes exist as quiescent astrocytes with barely detectable levels of EGFR. EGFR inhibitors will induce the transition from reactive astrocytes (which are seen in pathologic conditions such as NDD and SCI) to quiescent astrocytes through deactivating the EGFR. 
causes microtubule disassembly and axonal degeneration (Wakatsuki et al., 2015; Wakatsuki and Araki, 2016). The same pathway in soma activates EGFR and downstream ZNRF1 signaling pathway, which leads to an increase in the caspase 3 cleavage, annexin V-positive staining, lactate dehydrogenase release, and neuronal apoptosis. Knocking down EGFR or treatment with EGFR inhibitors prevents neuronal degeneration induced by oxidative stress (Wakatsuki et al., 2015; Wakatsuki and Araki, 2016). This activation of EGFR in both astrocytes and neurons caused by the pathologic conditions indicates an important role of EGFR and its downstream signaling pathway in neuronal degeneration and brain injuries.

\section{EGFR Inhibition in Neurodegenerative Diseases}

There are few reports showing the neuroprotective effect of EGFR inhibition in neurodegenerative diseases such as AD and ALS (Chiang et al., 2010; Wang et al., 2012a, 2013, 2017; Le Pichon et al., 2013; Chen et al., 2018). There are several main points arising from these reports that can be considered for any future proof-of-concept animal studies using EGFR inhibitors as therapeutics in NDDs.

Chen et al. (2018) first showed an association of polymorphism in three EGFR single nucleotide polymorphisms (SNPs) with the risk of $\mathrm{AD}$. In this study, the genetic association of three known cancer-related EGFR SNP sites (rs730437, rs3752651, and rs1468727) was studied in a Chinese Han population (139 patients with $\mathrm{AD}$ and 152 healthy control individuals). Polymorphism in two of these sites (rs730437 and rs1468727) showed a significant association with the development of $\mathrm{AD}$ (Chen et al., 2018). Frequencies of CC genotype and $\mathrm{C}$ allele of rs730437, compared with the controls (AA genotype and A allele), were significantly lower in the patients with $\mathrm{AD}$, showing that polymorphism of rs730437 is protective against the risk of $\mathrm{AD}$. In the case of other SNPs ( $r$ 1468727), the presence of the TT genotype (TT vs. CC) is associated with a reduced risk of $\mathrm{AD}$, but the frequency of $\mathrm{T}$ allele ( $\mathrm{T}$ vs. $\mathrm{C}$ ) is significantly higher in $\mathrm{AD}$ patients. Furthermore, linkage disequilibrium analysis of EGFR polymorphisms showed that the A-C-C haplotype (Site1-rs730437; site2-rs3752651; site3-rs1468727) was significantly correlated with an increased risk of $\mathrm{AD}$ compared with the A-T-T haplotype in the control (Chen et al., 2018). In addition to this recent genetics study, the first clues of involvement of the EGFR pathway in the development of $\mathrm{AD}$ were reported by Wang et al. and Chaing et al. (Chiang et al., 2010; Wang et al., 2012a). They have shown that fruit flies overexpressing A $\beta 42$ have severe memory loss and represent hyperactivity of the phosphoinositide 3-kinase (PI3K) pathway. The A $\beta 42$-induced memory loss in flies was prevented by knocking down the PI3K pathway regulatory subunit $\mathrm{P} 60$ or by pharmacological inhibition of PI3K functions using its specific inhibitor, wortmannin (Chiang et al., 2010). The authors then investigated the upstream receptor responsible for this neuroprotective pathway among the receptors associated with this PI3-kinase effect, insulin receptor, and EGFR by evaluating behavioral changes of receptor overexpression in memory loss of flies. The results showed that co-overexpression of $\mathrm{A} \beta 42$ and EGFR led to a high level of memory loss in flies and suggested the role of EGFR in the pathology of AD (Chiang et al., 2010). Following this study, the first report that characterized EGFR as a target for $\mathrm{AD}$ therapy was also published by Wang et al. (2012) (Wang et al., 2012a). The novel findings in this study are that 1) EGFR is activated by oligomeric $\mathrm{A} \beta 42$ in cell cultures, 2) the level of activated EGFR ( $\mathrm{p}$-EGFR/EGFR) is increased in Amyloid Precursor Protein (APP)/presenilin-1(PS1) double transgenic mice, and 3) EGFR inhibition rescues memory loss in APP/PS1 double transgenic mice and $\mathrm{A} \beta 42$ overexpression transgenic fruit flies (Wang et al., 2012a). Cell culture studies using COS-7 cells overexpressing human wild-type EGFR (WT-EGFR) confirmed that treatment with synthetic oligomers of $\mathrm{A} \beta 42(25 \mu \mathrm{g} / \mathrm{ml})$ generated in vitro led to an elevation in the level of p-EGFR in the Western Blot (WB) analysis. Furthermore, treatment of cells with EGFR inhibitors (gefitinib and erlotinib) rescues $\mathrm{A} \beta 42$-induced EGFR activation. The authors also investigated the direct binding of $\mathrm{A} \beta 42$ oligomers to EGFR using coimmunoprecipitation in COS-7 cells, expressing a secretory form of $\mathrm{A} \beta 42$ and human WT-EGFR. The results indicated that endogenously produced $\mathrm{A} \beta 42$ species were pulled down with EGFR, which suggested the direct binding of these amyloid structures with EGFR (Wang et al., $2012 \mathrm{a}$ ). The activation of EGFR by A $\beta 42$ was also investigated further in a double transgenic mouse model that expressed a mutant chimeric mouse/human APPswe and a mutant human presenilin 1 (Delta E9), both driven by the prion protein promoter (APP/PS1 double transgenic mice). WB analysis of hippocampus lysates ( $n=4$ mice/group) showed an elevation in the level of activated EGFR (p-EGFR/EGFR) compared with the wild-type mice. This activation was suppressed by administration of an EGFR inhibitor, gefitinib, for 18 days at $10 \mathrm{mg} / \mathrm{kg}$ per day. After this pharmacokinetic evaluation of gefitinib in the mouse brain, the efficacy of gefitinib and erlotinib to improve $\mathrm{A} \beta 42$-induced memory loss was tested in fruit flies overexpressing a secretory form of human $\mathrm{A} \beta 42$ in the brain. Male flies at 3 days old were treated with different doses of these EGFR inhibitors $(0.01$, $0.1,1$, and $10 \mu \mathrm{g} / \mathrm{ml}$ ) for 7 days. In almost all doses of both drug regimens, the memory loss was rescued significantly. This improvement was concentration-dependent for gefitinib, whereas in the case of erlotinib, the improvement was not concentrationdependent (Wang et al., 2012a). The efficacy of gefitinib in rescuing memory loss was also investigated in APP/PS1 double transgenic mice. This mouse model shows high levels of amyloid plaques as well as a memory-loss phenotype at 6-9 months of age. Thus, in this study, short-term treatment of 18 days starting at 8 months of age was used to evaluate any improvements in Morris water maze. Results demonstrated that gefitinib, at a minimum dose of $0.01 \mathrm{mg} / \mathrm{kg}$ per day, is efficient in rescuing memory loss in this model. Biochemical studies of mice brains in gefitinib-treated and control groups using WB of hippocampus lysates and Thioflavin-S staining $(n=3$ mice/group) showed a reduction in the level of oligomer/monomer and plaque area at a $10 \mathrm{mg} / \mathrm{kg}$ per day dose, but the results were not statistically significant (Wang et al., 2012a). We suggest that this statistically non-significant reduction might be due to insufficient power of the study as well as using a general amyloid staining method (i.e., Thioflavin-S staining) to detect amyloid plaques instead of immunohistochemical analysis of brain section using marker-specific antibodies. The same authors in another paper have shown that the role of EGFR in $\mathrm{AD}$ pathology depends on age (Wang et al., 2013). In the young flies ( 10 days old) expressing human pan-A $\beta 42$ (showing early stages of $\mathrm{AD}$ phenotypes), the level of EGFR is raised, and at this stage, $\mathrm{A} \beta 42$ activates EGFR/PI3K, disrupts the normal 
synaptic plasticity, and, at the end, leads to memory loss phenotype. But in the aged flies (35 days old) showing the late stages of $\mathrm{AD}$ pathology and memory loss, $\mathrm{A} \beta 42$ causes a significant reduction in the level of EGFR, which ends in neuronal degeneration. Moreover, despite reduction in the level of total EGFR and p-EGFR (normalized to actin) in APP/PS1 double transgenic mice at 8 months of age, the level of activated EGFR (p-EGFR/EGFR) is significantly increased compared with wild-type mice (Wang et al., 2013). In another study, an irreversible EGFR inhibitor, CL-387,785, was used to study the neuroprotective effect of EGFR inhibition in cell cultures, zebrafish, and a mouse model of AD (APP/PS1 double transgenic mice) (Wang et al., 2017). This inhibitor causes a significant reduction in p62 and a concurrent increase in the microtubule-associated protein 1A/1B-light chain 3 (LC3) ratio (LC3-II/LC3-I ratio); it subsequently leads to the autophagy activation, which finally facilitates degradation and clearance of $\mathrm{A} \beta 40$ and $\mathrm{A} \beta 42$. Comparing the efficacy of gefitinib and CL-387,785 in APP/PS1 double transgenic mice shows that both inhibitors rescue memory loss in this model, but CL-387,785, even at lower doses ( $5 \mathrm{mg} / \mathrm{kg}$ per day), ameliorates pathologic markers by induction of autophagy (Wang et al., 2017). This might be due to the $\mathrm{IC}_{50}$ value of CL-387,785, which is 10 fold more efficient in EGFR inhibition compared with gefitinib or erlotinib (Greulich et al., 2005; Kobayashi et al., 2005; Engelman et al., 2006; Yu et al., 2007). In another study, the therapeutic benefit of EGFR inhibition using erlotinib was studied in a SOD1 mouse model of ALS, i.e., SOD1 ${ }^{\text {G93A }}$ mice that express a G93A mutant form of human SOD1 (Le Pichon et al., 2013). In this study, two separate experimental designs were used to evaluate the effect of erlotinib therapy in behavioral tests, body weight and survival (first experimental design) as well as histology (second experimental design). Though treatment started at 5 weeks of age in both experimental designs, dosage and duration of drug administration were different in these designs. In the first experimental design, mice were treated with $75 \mathrm{mg} / \mathrm{kg}$ per day for more than 4 months, but in the second experimental design, a lower dose (60 $\mathrm{mg} / \mathrm{kg}$ per day) of erlotinib was administrated for a shorter time (1 month). The results of the first experimental design showed that erlotinib therapy ameliorated weight loss and resulted in improvement of behavioral tests, including wire hang and balance beam, but this therapy had no effect on survival rate. The second experimental design failed in protecting motor synapses and did not modulate the number of GFAP- or ionized calcium-binding adapter molecule 1-positive cells as markers for astrocytes and microglia (Le Pichon et al., 2013). This unsuccessful pathology result might be due to using different dosing regimens in the second experimental design, which is less than the dose in the first experimental design, and the shorter administration time.

\section{EGFR Inhibition in the Brain and Spinal Cord Injuries}

Brain and spinal cord injuries upregulate EGFR level and its kinase activity in astrocytes, leading to transformation of quiescent astrocytes to reactive astrocytes, which are high proliferative cells that express GFAP marker of astrogliosis as well as secrete inhibitory molecules and proinflammatory cytokines/mediators such as chondroitin sulfate proteoglycans (CSPGs), tumor necrosis factor alpha (TNF- $\alpha$ ), inducible nitric oxide synthase, cyclooxygenase-2, and interleukin (IL)- $1 \beta$. These changes finally lead to glial scar formation, demyelination, and loss of oligodendrocytes and neurons. Administration of EGFR inhibitors ameliorates pathologic markers associated with these injuries (Liu and Neufeld, 2004; Zhang and Neufeld, 2005; Liu et al., 2006; Erschbamer et al., 2007; Li et al., 2011, 2014; Yang et al., 2011; Qu et al., 2012; Kjell et al., 2014; Zhang et al., 2016; Chen et al., 2017). In a traumatic brain injury rat model induced by weight-drop technique, AG1478 administration rescues EGFR activation and GFAP production to the level of noninjured samples (Li et al., 2011). Furthermore, EGFR inhibition by AG1478 alleviates spinal cord myelin loss and reduces the level of CSPGs. Moreover, growth-associated protein-43, a marker of regenerating neurons, was increased by EGFR suppression. These beneficial effects also correlate with the prevention of body weight loss as well as improvement in behavioral measurements of openfield locomotor testing ( $\mathrm{Li}$ et al., 2011). In another study, Zhang et al. (2016) showed that in a mouse model of SCI generated by laminectomy, treatment with the EGFR inhibitor PD168393 resulted in an increase in the expression of myelin basic protein and remyelination of axons in injured spinal cord as well as a reduction in the number of GFAP-expressing astrocytes. Furthermore, EGFR inhibition increased the number of oligodendrocyte precursor cells, which subsequently differentiate to form mature oligodendrocytes (Zhang et al., 2016). EGFR inhibition using PD168393 was also studied in the astrocyte scratch injury model in vitro and the weight-drop SCI rat model in vivo ( $\mathrm{Li}$ et al., 2014). Astrocytes in cultures were scratched with the sterile plastic pipette tips and treated with PD168393 (20 and $40 \mu \mathrm{M})$. EGFR inhibition in this in vitro scratch wound model reduces p-EGFR, GFAP, and secretion of astroglial cell proinflammatory cytokine (TNF- $\alpha$, inducible nitric oxide synthase, cyclooxygenase-2, and IL-1 $\beta$ ) (Li et al., 2014). Administration of PD168393 to SCI mouse model also leads to a significant diminish in p-EGFR, GFAP, demyelination, and production of CSPGs. Furthermore, PD168393 therapy improves locomotion and bladder function recovery in SCI rats assessed by Basso, Bresnahan, and Beattie hindlimb locomotion rating scale and recording residual urine volume of rats every day (Li et al., 2014). Erschbamer et al. (2007) also applied PD168393 in the same animal model (weight-drop SCI rat model) and have shown the same therapeutic benefits of EGFR inhibition in this model as well as an increase in the level of tyrosine hydroxylase and 5-hydroxytryptamine immunoreactive axons. In another study, erlotinib was administrated at $5 \mathrm{mg} / \mathrm{kg}$ per day to the weight-drop SCI rat model for 5 days postinjury (Kjell et al., 2014). The results confirmed an improvement in both locomotion and bladder function recovery (Kjell et al., 2014). Not only were small molecule inhibitors of EGFR used as astrogliosis therapy in SCI, but monoclonal antibody therapy was also successfully used in both in vitro and animal studies to inhibit EGFR activation and downstream pathways (Yang et al., 2011; Qu et al., 2012). A human-mouse chimeric anti-EGFR monoclonal neutralizing antibody, C225, which is currently in the clinic for treatment of cancers associated with EGFR overexpression, was tested to target EGFR upregulation in SCIs (Yang et al., 2011; Qu et al., 2012). Yang et al. (2011) generated reactive astrocytes by OGD/reoxygenation induction. Pretreatment of these cells before OGD/reoxygenation induction with C225 (10 lg/ml) resulted in significant reduction in p-EGFR, GFAP expression, 
and astrocyte proliferation. Administration of C225 (106 lg/day) for a minimum of 3 days in a transient ( 1 hour) middle cerebral artery occlusion rat model rescues p-EGFR- and GFAPpositive astrocytes phenotypes (Yang et al., 2011). Qu et al. (2012) also tested the efficacy of C225 in ameliorating EGFR activation in injury-induced activated microglia in vitro and in vivo. Microglia cells were treated with C225 (20 nM), and 30 minutes later, cells were activated by adding lipopolysaccharide $(1 \mu \mathrm{g} / \mathrm{ml})$ (Qu et al., 2012). The traumatic SCI rat model was generated by the weight-drop technique. Results demonstrated a significant reduction in the p-EGFR and production of cytokines such as IL- $1 \beta$ and TNF- $\alpha$ in both cell culture and rat model treated with C225 (Qu et al., 2012).

\section{Molecular Mechanisms for the Neuroprotective Effect of EGFR Inhibition}

Two possible and main molecular mechanisms are proposed for the neuroprotective effect of EGFR inhibition in NDDs and SCI. The first one is to rescue reactive astrocyte pathology, which is discussed above (Erschbamer et al., 2007; Li et al., 2011, 2014; Yang et al., 2011; Qu et al., 2012; Kjell et al., 2014; Zhang et al., 2016). The second one is the induction of autophagy, leading to degradation of toxic amyloid structures such as amyloid- $\beta$ aggregates. In mammalian cells, autophagy is generally a stress response that is triggered to keep the cellular homeostasis and survival (Tavassoly, 2015). Autophagy in cancer is a mechanism to stop cell death and is a significant component of resistance to therapies (Tavassoly et al., 2015). EGFR inhibits autophagy through blocking Belin-1 (Wei et al., 2013). The complexity of crosstalk between autophagy and EGFR is controlled by the mammalian target of rapamycin (mTOR). Because suppression of mTOR induces autophagy and suppresses cell growth, feedback loops between cellular growth pathways and autophagy are organized in a way such that inhibition of cellular growth pathways (such as EGFR inhibition) is associated with increased autophagy (El-Rayes and LoRusso, 2004; Dorvash et al., 2019, 2020) (Figs. 2 and 3).

Although autophagy is a characteristic of malignant cells in the contexts of neoplasia and cancer (Hanahan and Weinberg, 2011), in neurodegeneration, autophagy is a cleanup process that keeps the neurons safe against aggregation of damaged proteins and organelles (Wong and Cuervo, 2010). In other words, autophagy is a protective mechanism against aging and neurodegeneration in neurons. Because oxidative stress and cell death occurs in brain injuries, activating the autophagy is a good intervention to help overcome the injury and keep the neuronal homeostasis (Lipinski et al., 2015) (Fig. 2). When all these pathways are studied on a systems-level scale, it becomes clear that the network dynamics of cellular growth, autophagy, and cell death indicate the inhibition of EGFR to be beneficial as a therapeutic intervention in NDDs and SCI, whereas in cancer, EGFR antagonists can increase autophagy and cause resistance in particular conditions. The inhibition of EGFR will induce the activation of autophagy in all these cases. In cancer, EGFR inhibition stops cell proliferation and, at the same time, causes increased autophagy. Autophagy has a dual role in cancer; if it is activated beyond the cellular capacity, it turns on the cell death pathways when the autophagy level surpasses its rheostat capacity (Tavassoly et al., 2015). Rheostat capacity of autophagy is the level at which autophagy is cytoprotective, and in cancer, activation of autophagy at this level is a part of cancer hallmarks and can eventually lead to resistance to therapy. In NDDs and SCI, EGFR inhibition induces autophagy as a repair and quality control mechanism and can be a therapeutic intervention. In cancer cells, though higher doses of EGFR antagonists are needed to trigger cell death, ineffective doses only increase autophagy and can cause therapeutic resistance and increased tumor progression. This can be concluded from the dynamical models of autophagy and apoptosis in cancer (Tyson et al., 2011; Tavassoly et al., 2015; Dorvash et al.,

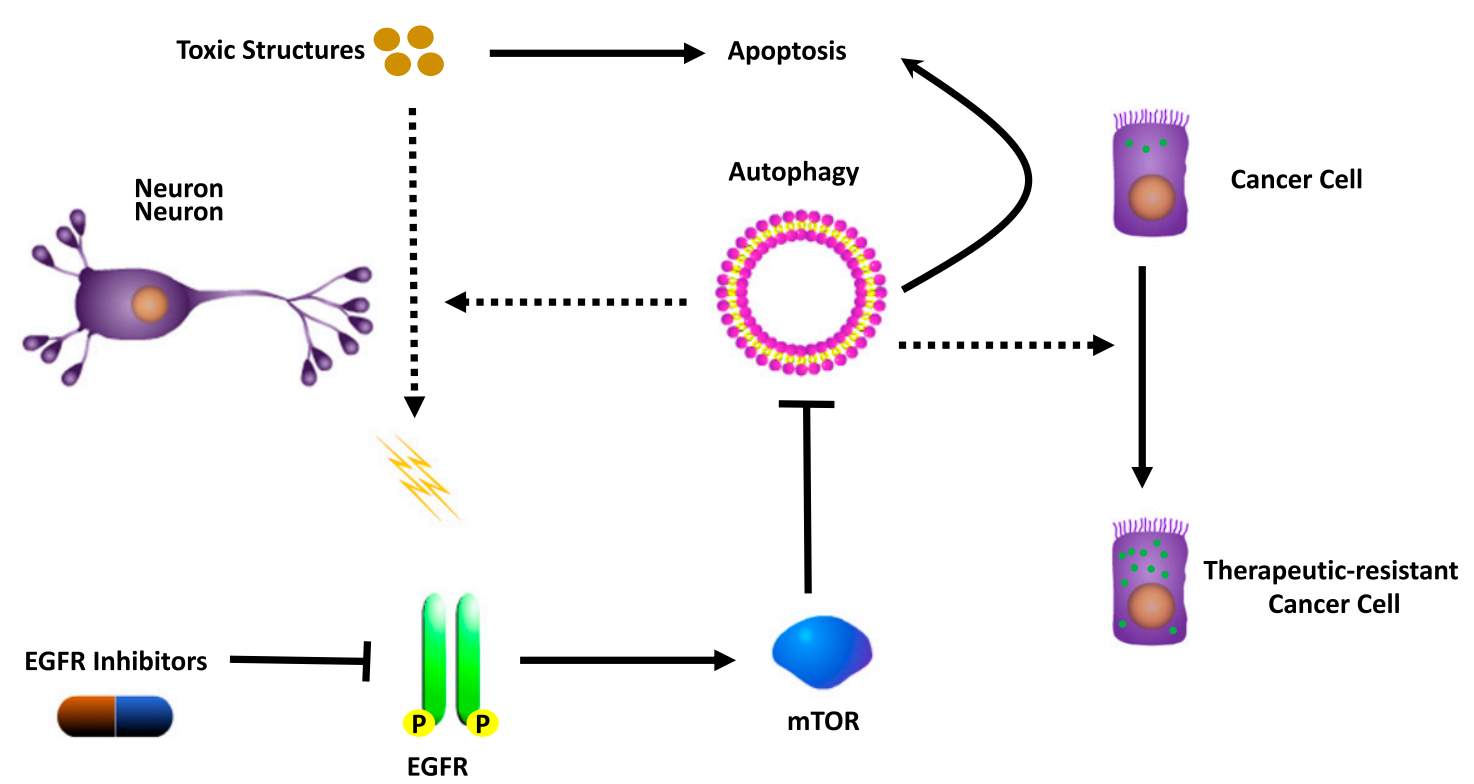

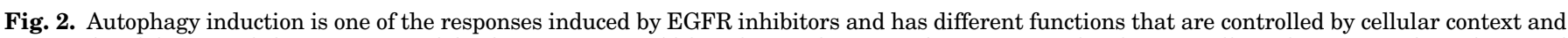

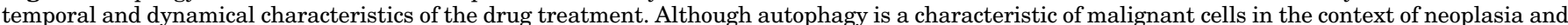
cancer, in neurodegeneration, autophagy is a cleanup process that keeps the neurons safe against aggregation of damaged proteins and organelles. 


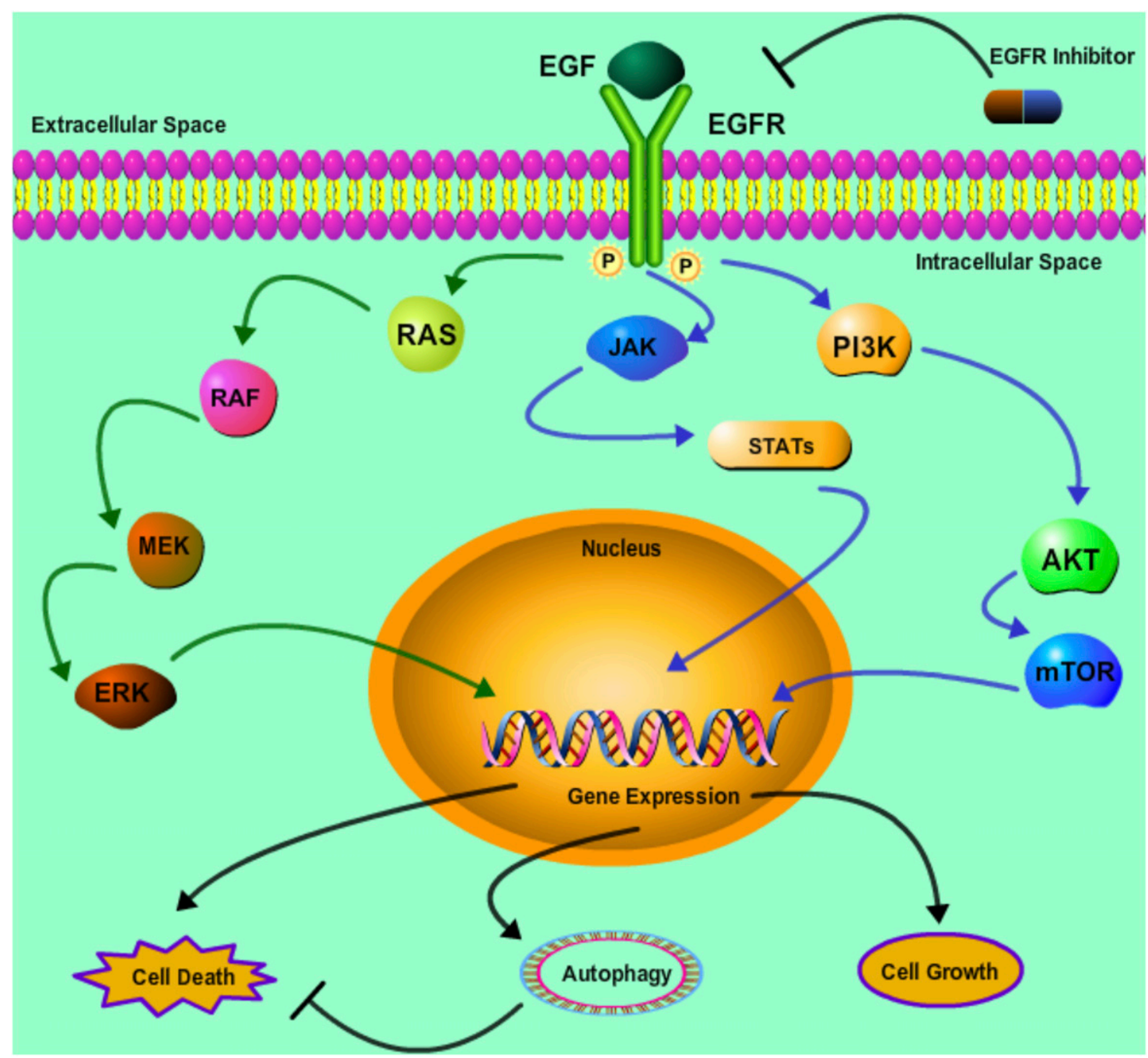

Fig. 3. Cell fate decision controlled by EGFR signaling pathway. Activation of EGFR leads to a series of activated pathways that can turn on cellular processes, including cell death, autophagy, and cell growth. The signaling pathways involved in transducing EGFR activation signal include mTOR, Janus Kinase/Signal Transducer and Activator of Transcription Protein (JAK/STAT), and RAS.

2020). In a recently published paper, the connection between EGFR inhibition and induction of autophagy in $\mathrm{AD}$ was reported (Wang et al., 2017). Administration of an EGFR inhibitor (CL-387,785, $5 \mathrm{mg} / \mathrm{kg}$ per day) to APP/presenilin-1 (PS1) transgenic mice for 3 weeks increased the level of autophagy and finally led to a reduction in the level of both $\beta \mathrm{A} 40$ and $\beta \mathrm{A} 42$ and a significant improvement of memory loss phenotype (Wang et al., 2017).

\section{Recent Advances in the Development of BBB EGFR Inhibitors}

Although EGFR tyrosine kinase inhibitors such as gefitinib and erlotinib can be used in the brain cancer metastasis, they have not shown significant and persistent effects. Generally, targeting brain tumors or brain metastasis, which can benefit from EGFR antagonists, is challenging because classic EGFR antagonists are not capable of penetrating the BBB (Ahluwalia et al., 2018). The doses needed to affect the tumor progression are beyond the safe doses and are not applicable. The new generation of BBB-penetrating EGFR antagonists such as osimertinib and AZD3759 has shown promising effects in stopping cancer progression in the brain, both in preclinical and early-phase clinical trials (Ciardiello and Tortora, 2008; Kim et al., 2015; Ahn et al., 2016; Yang et al., 2016). Furthermore, despite the availability of pharmacokinetics and pharmacodynamics parameters of most of the EGFR inhibitors, these values are measured in cancer-related animal models and might not be suitable for the purpose of NDDs and SCI therapies. There is a need for characterizing pharmacokinetics and pharmacodynamics parameters of BBB-penetrating EGFR inhibitors in NDDs and SCI-related models. Moreover, $\mathrm{IC}_{50}$ values of these drugs are characterized in cancer cell lines carrying upregulated or mutant forms of EGFR, and these concentrations might be toxic for neurons or reactive astrocytes. These values must be assessed in CNS-related cells and correlated with cell viability measurements to find the most effective but nontoxic dose suitable for any future CNS-related cell culture studies. A list of EGFR inhibitor and their characteristics and clinical indications are provided in Table 1 (Muhsin et al., 2003; Ciardiello et al., 2004; Thomas and Grandis, 2004, Dowell et al., 2005; Goldberg and Kirkpatrick, 2005; Saltz et al., 2006; Moy et al., 2007; Ciardiello and Tortora, 2008; Messersmith and Ahnen, 2008; 
TABLE 1

List of the EGFR inhibitors, their properties, and clinical indications

\begin{tabular}{|c|c|c|c|c|c|}
\hline \multirow[b]{2}{*}{ Drug Name } & \multirow[b]{2}{*}{ Brand Name } & \multirow[b]{2}{*}{ Inhibition Site } & \multirow[b]{2}{*}{ Clinical Indication } & \multicolumn{2}{|c|}{ BBB Penetration } \\
\hline & & & & $\begin{array}{l}\text { CSF Penetration } \\
\text { Rate (\%) in Patients }\end{array}$ & $\begin{array}{l}\text { Brain Penetration Rate } \\
(\%) \text { in Animal Models }\end{array}$ \\
\hline Erlotinib & Tarceva & ATP binding site & $\begin{array}{l}\text { NSCLC and pancreatic } \\
\text { cancer }\end{array}$ & $2.77-5.1$ & 13.7 \\
\hline Gefitinib & Iressa & ATP binding site & NSCLC & $1.07-3.58$ & 27 \\
\hline Afatinib & Gilotrif & ATP binding site & NSCLC & 0.7 & ND \\
\hline Brigatinib & Alunbrig & ATP binding site of ALK & NSCLC & ND & ND \\
\hline Icotinib & Conmana & ATP binding site & NSCLC & 0.35 & 2.69 \\
\hline Cetuximab & Erbitux & Domain III of sEGFR & $\begin{array}{l}\text { Colorectal cancer, } \\
\text { NSCLC, head and neck } \\
\text { cancer }\end{array}$ & ND & ND \\
\hline Osimertinib & Tagrisso & ATP binding site & NSCLC & ND & 180 \\
\hline Lapatinib & $\begin{array}{l}\text { Tykerb and } \\
\text { Tyverb }\end{array}$ & $\begin{array}{l}\text { ATP-binding pocket of the EGFR/ } \\
\text { HER2 protein kinase domain }\end{array}$ & Breast cancer & ND & ND \\
\hline Panitumumab & Vectibix & Extracellular domain of the EGFR & Colorectal cancer & ND & ND \\
\hline Neratinib & Nerlynx & $\begin{array}{l}\text { Cysteine side chain of EGFR/HER2 } \\
\text { protein kinase domain }\end{array}$ & Breast cancer & ND & ND \\
\hline Vandetanib & Caprelsa & $\begin{array}{l}\text { ATP binding site: inhibits RET, } \\
\text { VEGFR-2, VEGFR-3, EGFR and } \\
\text { VEGFR-1 }\end{array}$ & Medullary thyroid cancer & $1.2-2.4$ & 21 \\
\hline Necitumumab & Portrazza & Domain III of sEGFR & NSCLC & ND & ND \\
\hline Dacomitinib & Vizimpro & ATP binding site & NSCLC & ND & ND \\
\hline $\begin{array}{l}\text { AZD3759 (Phase I } \\
\text { Clinical Trial) }\end{array}$ & & ATP binding site & NSCLC & 111 & 282 \\
\hline
\end{tabular}

ND, not determined. ALK: anaplastic lymphoma kinase; RET: rearranged during transfection; VEGFR: vascular endothelial growth factor

Bose and Ozer, 2009; Dienstmann and Tabernero, 2010; Vecchione et al., 2011; Leboulleux et al., 2012; Brzezniak et al., 2013; Yu and Pao, 2013; Tan et al., 2015, 2017; Wei et al., 2016; Karachaliou et al., 2018; Kim et al., 2019; Spencer et al., 2019; Takeda and Nakagawa, 2019).

\section{Discussion and Conclusion}

NDDs and SCI are common CNS diseases affecting many patients worldwide, and every year the number of these patients increases. There are treatments to control symptoms of these diseases, yet there is no cure to stop or prevent their progression. Finding novel therapeutics requires detailed knowledge about molecular mechanisms of these diseases to target the pathologic marker or pathways. Systems biology and systems pharmacology methodologies are helpful to understand the pathologic complex mechanism causing these diseases and their vulnerabilities for precision therapeutic targeting (Tavassoly et al., 2018; Dorvash et al., 2019). Even though these diseases have specified molecular mechanisms and markers, they have common pathologic features that might be due to a common molecular mechanism behind CNS diseases. Some pieces of evidence suggest EGFR activation as a common pathologic pathway in these diseases, which finally causes neuronal apoptosis and degeneration. Targeting EGFR activation might be a novel therapy in both NDDs and SCI. There are several EGFR inhibitors at clinical level for cancer therapy that have the potential to be repositioned for these diseases. In this review, we summarized and collected all reports on the role of EGFR in the pathologic development of these diseases and emphasized the need for considering EGFR as a novel target in NDDs and SCI. There are two possible molecular mechanisms for EGFR inhibition, autophagy induction and rescuing reactive astrocyte, which are known to improve both behavioral and pathologic hallmarks of these diseases. Unfortunately, there are few studies showing the therapeutic benefits of EGFR inhibition, especially in NDDs, which might be due to ambiguous information about the role of EGFR in pathology development of these diseases. Our attempt in this paper was to collect all information in this regard and open a new route for future studies targeting EGFR. There are some concerns arising from the previous studies that should be considered. Concentrations and doses of these inhibitors need to be adjusted for the purpose of EGFR targeting in neuronal cell cultures and noncancer animal models. Also, using novel BBB-penetrating EGFR inhibitors is recommended. Overall, we conclude that inhibition of EGFR activation in NDDs and SCI can be a potential strategy for preventing and stopping neurodegeneration and neuronal apoptosis.

\section{Authorship Contributions}

Wrote or contributed to the writing of the manuscript: $\mathrm{O}$. Tavassoly, Sato, I. Tavassoly.

\section{References}

Abjean L, Haim LB, Sauvage MAC, Hérard A-S, Derbois C, Petit F, Gipstein P, Guillermier M, Gaudin M, Bernier S, et al. (2018) A42 Reactive astrocytes promote proteostasis in huntington's disease. J Neurol Neurosurg Psychiatry 89 (Suppl 1): A15.

Ahluwalia MS, Becker K, and Levy BP (2018) Epidermal growth factor receptor tyrosine kinase inhibitors for central nervous system metastases from non-small cell lung cancer. Oncologist 23:1199-1209.

Ahn M-J, Kim D-W, Kim TM, Lin C-C, Ratnayake J, Carlie DJ, Yin X, Yang Z, Jiang H, and Yang JC-H (2016) Phase I study of AZD3759, a CNS penetrable EGFR inhibitor, for the treatment of non-small-cell lung cancer (NSCLC) with brain metastasis (BM) and leptomeningeal metastasis (LM), J Clin Oncol 34, p 9003.

Avraham R and Yarden Y (2011) Feedback regulation of EGFR signalling: decision making by early and delayed loops. Nat Rev Mol Cell Biol 12:104-117.

Bandopadhyay R, Kingsbury AE, Cookson MR, Reid AR, Evans IM, Hope AD, Pittman AM, Lashley T, Canet-Aviles R, Miller DW, et al. (2004) The expression of DJ-1 (PARK7) in normal human CNS and idiopathic Parkinson's disease. Brain 127:420-430.

Berasain C and Avila MA (2014) Amphiregulin, Semin Cell Dev Biol 28, pp 31-41.

Birecree E, Whetsell WO Jr., Stoscheck C, King LE Jr., and Nanney LB (1988) Immunoreactive epidermal growth factor receptors in neuritic plaques from patients with Alzheimer's disease. J Neuropathol Exp Neurol 47:549-560.

Booth HDE, Hirst WD, and Wade-Martins R (2017) The role of astrocyte dysfunction in Parkinson's disease pathogenesis. Trends Neurosci 40:358-370. 
Bose P and Ozer H (2009) Neratinib: an oral, irreversible dual EGFR/HER2 inhibitor for breast and non-small cell lung cancer. Expert Opin Investig Drugs 18:1735-1751. Brzezniak C, Carter CA, and Giaccone G (2013) Dacomitinib, a new therapy for the treatment of non-small cell lung cancer. Expert Opin Pharmacother 14:247-253.

Carpenter G and Cohen S (1990) Epidermal growth factor. J Biol Chem 265: 7709-7712.

Ceyzériat K, Ben Haim L, Denizot A, Pommier D, Matos M, Guillemaud O, Palomares M-A, Abjean L, Petit F, Gipchtein P, et al. (2018) Modulation of astrocyte reactivity improves functional deficits in mouse models of Alzheimer's disease. Acta Neuropathol Commun 6:104.

Chavarría C, Rodríguez-Bottero S, Quijano C, Cassina P, and Souza JM (2018) Impact of monomeric, oligomeric and fibrillar alpha-synuclein on astrocyte reactivity and toxicity to neurons. Biochem J 475:3153-3169.

Chen J, He W, Hu X, Shen Y, Cao J, Wei Z, Luan Y, He L, Jiang F, and Tao Y (2017) A role for ErbB signaling in the induction of reactive astrogliosis. Cell Discov 3:17044

Chen X, Wang C, Zhou S, Li X, and Wu L (2018) The impact of EGFR gene polymorphisms on the risk of Alzheimer's disease in a Chinese han population: a case-controlled study. Med Sci Monit 24:5035-5040.

Chiang H-C, Wang L, Xie Z, Yau A, and Zhong Y (2010) PI3 kinase signaling is involved in Abeta-induced memory loss in Drosophila. Proc Natl Acad Sci USA 107: $7060-7065$

Ciardiello F, De Vita F, Orditura M, and Tortora G (2004) The role of EGFR inhibitors in nonsmall cell lung cancer. Curr Opin Oncol 16:130-135.

Ciardiello F and Tortora G (2008) EGFR antagonists in cancer treatment. $N$ Engl $J$ Med 358:1160-1174.

Dhaunsi GS, Alsaeid M, and Akhtar S (2016) Phytanic acid activates NADPH oxidase through transactivation of epidermal growth factor receptor in vascular smooth muscle cells. Lipids Health Dis 15:105.

Dienstmann R and Tabernero J (2010) Necitumumab, a fully human IgG1 mAb directed against the EGFR for the potential treatment of cancer. Curr Opin Investig Drugs 11:1434-1441.

Diniz LP, Matias I, Araujo APB, Garcia MN, Barros-Aragão FGQ, Alves-Leon SV, de Souza JM, Foguel D, Figueiredo CP, Braga C, et al. (2019) $\alpha$-synuclein oligomers enhance astrocyte-induced synapse formation through TGF- $\beta 1$ signaling in a Parkinson's disease model. J Neurochem 150:138-157.

Dorvash M, Farahmandnia M, Mosaddeghi P, Farahmandnejad M, Saber H, Khorraminejad-Shirazi M, Azadi A, and Tavassoly I (2019) Dynamic modeling of signal transduction by mTOR complexes in cancer. J Theor Biol 483:109992.

Dorvash M, Farahmandnia M, and Tavassoly I (2020) A systems biology roadmap to decode mTOR control system in cancer. Interdiscip Sci 12:1-11.

Dowell J, Minna JD, and Kirkpatrick P (2005) Erlotinib Hydrochloride, Nature Publishing Group, Berlin, Germany.

Duffy MF, Collier TJ, Patterson JR, Kemp CJ, Luk KC, Tansey MG, Paumier KL, Kanaan NM, Fischer DL, Polinski NK, et al. (2018) Lewy body-like alpha-synuclein inclusions trigger reactive microgliosis prior to nigral degeneration. $J$ Neuroinflammation 15:129.

Dunbar AJ and Goddard C (2000) Structure-function and biological role of betacellulin. Int $J$ Biochem Cell Biol 32:805-815.

El-Rayes BF and LoRusso PM (2004) Targeting the epidermal growth factor receptor. Br J Cancer 91:418-424.

Engelman JA, Mukohara T, Zejnullahu K, Lifshits E, Borrás AM, Gale C-M, Naumov GN, Yeap BY, Jarrell E, Sun J, et al. (2006) Allelic dilution obscures detection of a biologically significant resistance mutation in EGFR-amplified lung cancer. J Clin Invest 116:2695-2706.

Enwere E, Shingo T, Gregg C, Fujikawa H, Ohta S, and Weiss S (2004) Aging results in reduced epidermal growth factor receptor signaling, diminished olfactory neurogenesis, and deficits in fine olfactory discrimination. J Neurosci 24:8354-8365.

Erschbamer M, Pernold K, and Olson L (2007) Inhibiting epidermal growth factor receptor improves structural, locomotor, sensory, and bladder recovery from experimental spinal cord injury. $J$ Neurosci 27:6428-6435.

Faideau M, Kim J, Cormier K, Gilmore R, Welch M, Auregan G, Dufour N, Guillermier M, Brouillet E, Hantraye P, et al. (2010) In vivo expression of polyglutamine-expanded huntingtin by mouse striatal astrocytes impairs glutamate transport: a correlation with Huntington's disease subjects. Hum Mol Genet 19:3053-3067.

Forman MS, Lal D, Zhang B, Dabir DV, Swanson E, Lee VM-Y, and Trojanowski JQ (2005) Transgenic mouse model of tau pathology in astrocytes leading to nervous system degeneration. J Neurosci 25:3539-3550.

Frost GR and Li Y-M (2017) The role of astrocytes in amyloid production and Alzheimer's disease. Open Biol 7.

Fung C, et al. (2012) EGFR tyrosine kinase inhibition induces autophagy in cancer cells. Cancer biology \& therapy, doi: 10.4161/cbt.22002.

Galvez-Contreras AY, Quiñones-Hinojosa A, and Gonzalez-Perez O (2013) The role of EGFR and ErbB family related proteins in the oligodendrocyte specification in germinal niches of the adult mammalian brain. Front Cell Neurosci 7:258.

Goldberg R and Kirkpatrick P (2005) Cetuximab. Nat Rev Drug Discov 4:S10-S11.

González-Reyes RE, Nava-Mesa MO, Vargas-Sánchez K, Ariza-Salamanca D, and Mora-Muñoz L (2017) Involvement of astrocytes in Alzheimer's disease from a neuroinflammatory and oxidative stress perspective. Front Mol Neurosci 10:427.

Greulich H, Chen TH, Feng W, Jänne PA, Alvarez JV, Zappaterra M, Bulmer SE, Frank DA, Hahn WC, Sellers WR, et al. (2005) Oncogenic transformation by inhibitor-sensitive and -resistant EGFR mutants. PLoS Med 2:e313.

Gu X, Li C, Wei W, Lo V, Gong S, Li S-H, Iwasato T, Itohara S, Li X-J, Mody I, et al. (2005) Pathological cell-cell interactions elicited by a neuropathogenic form of mutant Huntingtin contribute to cortical pathogenesis in HD mice. Neuron 46:433-444

Hammoud L, Burger DE, Lu X, and Feng Q (2009) Tissue inhibitor of metalloproteinase-3 inhibits neonatal mouse cardiomyocyte proliferation via EGFR/JNK/SP-1 signaling. Am J Physiol Cell Physiol 296:C735-C745.

Han W, et al. (2011) EGFR tyrosine kinase inhibitors activate autophagy as a cytoprotective response in human lung cancer cells. PloS one 6 (6), doi: 10.1371/journal.pone.0018691.
Hanahan D and Weinberg RA (2011) Hallmarks of cancer: the next generation. Cell 144:646-674.

Herbst RS (2004) Review of epidermal growth factor receptor biology. Int $J$ Radiat Oncol Biol Phys 59 (2 Suppl):S21-S26.

Iwakura Y, Piao YS, Mizuno M, Takei N, Kakita A, Takahashi H, and Nawa H (2005) Influences of dopaminergic lesion on epidermal growth factor-ErbB signals in Parkinson's disease and its model: neurotrophic implication in nigrostriatal neurons. J Neurochem 93:974-983.

Jo S, Yarishkin O, Hwang YJ, Chun YE, Park M, Woo DH, Bae JY, Kim T, Lee J, Chun $\mathrm{H}$, et al. (2014) GABA from reactive astrocytes impairs memory in mouse models of Alzheimer's disease. Nat Med 20:886-896.

Joe EH, Choi DJ, An J, Eun JH, Jou I, and Park S (2018) Astrocytes, microglia, and Parkinson's disease. Exp Neurobiol 27:77-87.

Kahlson MA and Colodner KJ (2015) Glial tau pathology in tauopathies: functional consequences. J Exp Neurosci 9 (Suppl 2):43-50.

Karachaliou N, Fernandez-Bruno M, Paulina Bracht JW, and Rosell R (2018) EGFR first-and second-generation TKIs-there is still place for them in EGFR-mutant NSCLC patients. Transl Cancer Res 8:S23-S47.

Kaser MR, Lakshmanan J, and Fisher DA (1992) Comparison between epidermal growth factor, transforming growth factor- $\alpha$ and EGF receptor levels in regions of adult rat brain. Brain Res Mol Brain Res 16:316-322.

Kim D-W, Yang JC-H, Chen K, Cheng Z, Yin L, Martin PD, Yang Z, Jiang H, and Ahn M-J (2015) AZD3759, an EGFR inhibitor with blood brain barrier (BBB) penetration for the treatment of non-small cell lung cancer (NSCLC) with brain metastasis (BM): preclinical evidence and clinical cases, J Clin Oncol 33, p 8016.

Kim M, Laramy JK, Mohammad AS, Talele S, Fisher J, Sarkaria JN, and Elmquist WF (2019) Brain distribution of a panel of epidermal growth factor receptor inhibitors using cassette dosing in wild-type and Abcb1/Abcg2-deficient mice. Drug Metab Dispos 47:393-404.

Kjell J, Pernold K, Olson L, and Abrams MB (2014) Oral erlotinib, but not rapamycin, causes modest acceleration of bladder and hindlimb recovery from spinal cord injury in rats. Spinal Cord 52:186-190.

Kobayashi S, Ji H, Yuza Y, Meyerson M, Wong K-K, Tenen DG, and Halmos B (2005) An alternative inhibitor overcomes resistance caused by a mutation of the epidermal growth factor receptor. Cancer Res 65:7096-7101.

Kolev V, Mandinova A, Guinea-Viniegra J, Hu B, Lefort K, Lambertini C, Neel V, Dummer R, Wagner EF, and Dotto GP (2008) EGFR signalling as a negative regulator of Notch1 gene transcription and function in proliferating keratinocytes and cancer. Nat Cell Biol 10:902-911.

Koprich JB, Reske-Nielsen C, Mithal P, and Isacson O (2008) Neuroinflammation mediated by IL-1 $\beta$ increases susceptibility of dopamine neurons to degeneration in an animal model of Parkinson's disease. J Neuroinflammation 5:8.

Kornblum HI, Hussain RJ, Bronstein JM, Gall CM, Lee DC, and Seroogy KB (1997) Prenatal ontogeny of the epidermal growth factor receptor and its ligand, transforming growth factor alpha, in the rat brain. J Comp Neurol 380:243-261.

Kushner PD, Stephenson DT, and Wright S (1991) Reactive astrogliosis is widespread in the subcortical white matter of amyotrophic lateral sclerosis brain. J Neuropathol Exp Neurol 50:263-277.

Laug D, Huang T-W, Huerta NAB, Huang AY-S, Sardar D, Ortiz-Guzman J, Carlson JC, Arenkiel BR, Kuo CT, Mohila CA, et al. (2019) Nuclear factor I-A regulates diverse reactive astrocyte responses after CNS injury. $J$ Clin Invest 129:4408-4418

Leboulleux S, Bastholt L, Krause T, de la Fouchardiere C, Tennvall J, Awada A, Gómez JM, Bonichon F, Leenhardt L, Soufflet C, et al. (2012) Vandetanib in locally advanced or metastatic differentiated thyroid cancer: a randomised, double-blind, phase 2 trial. Lancet Oncol 13:897-905.

Le Pichon CE, Dominguez SL, Solanoy H, Ngu H, Lewin-Koh N, Chen M, EasthamAnderson J, Watts R, and Scearce-Levie K (2013) EGFR inhibitor erlotinib delays disease progression but does not extend survival in the SOD1 mouse model of ALS. PLoS One 8:e62342.

Li Z-W, Li J-J, Wang L, Zhang J-P, Wu J-J, Mao X-Q, Shi G-F, Wang Q, Wang F, and Zou J (2014) Epidermal growth factor receptor inhibitor ameliorates excessive astrogliosis and improves the regeneration microenvironment and functional recovery in adult rats following spinal cord injury. J Neuroinflammation 11:71.

Li Z-W, Tang R-H, Zhang J-P, Tang Z-P, Qu W-S, Zhu W-H, Li J-J, Xie M-J, Tian D-S, and Wang W (2011) Inhibiting epidermal growth factor receptor attenuates reactive astrogliosis and improves functional outcome after spinal cord injury in rats. $\mathrm{Neu}$ rochem Int 58:812-819.

Lipinski MM, Wu J, Faden AI, and Sarkar C (2015) Function and mechanisms of autophagy in brain and spinal cord trauma. Antioxid Redox Signal 23:565-577.

Liu B, Chen H, Johns TG, and Neufeld AH (2006) Epidermal growth factor receptor activation: an upstream signal for transition of quiescent astrocytes into reactive astrocytes after neural injury. J Neurosci 26:7532-7540.

Liu B and Neufeld AH (2004) Activation of epidermal growth factor receptor causes astrocytes to form cribriform structures. Glia 46:153-168.

Liu B and Neufeld AH (2007) Activation of epidermal growth factor receptors in astrocytes: from development to neural injury. J Neurosci Res 85:3523-3529.

Liu L, Zhao Z, Yin Q, and Zhang X (2019) TTB protects astrocytes against oxygenglucose deprivation/reoxygenation-induced injury via activation of Nrf2/HO-1 signaling pathway. Front Pharmacol 10:792.

Lohmann S, Bernis ME, Tachu BJ, Ziemski A, Grigoletto J, and Tamgüney G (2019) Oral and intravenous transmission of $\alpha$-synuclein fibrils to mice. Acta Neuropathol 138:515-533.

Lupo G, Gioia R, Nisi PS, Biagioni S, and Cacci E (2019) Molecular mechanisms of neurogenic aging in the adult mouse subventricular zone. $J$ Exp Neurosci 13 1179069519829040

Messersmith WA and Ahnen DJ (2008) Targeting EGFR in colorectal cancer. $N$ Engl J Med 359:1834-1836.

Morizawa YM, Hirayama Y, Ohno N, Shibata S, Shigetomi E, Sui Y, Nabekura J, Sato K, Okajima F, Takebayashi H, et al. (2017) Reactive astrocytes function as phagocytes after brain ischemia via ABCA1-mediated pathway. Nat Commun 8:28. 
Moy B, Kirkpatrick P, Kar S, and Goss P (2007) Lapatinib, Nature Publishing Group, Berlin, Germany.

Muhsin M, Graham J, and Kirkpatrick P (2003) Gefitinib, Nature Publishing Group, Berlin, Germany.

Neumann M, Müller V, Görner K, Kretzschmar HA, Haass C, and Kahle PJ (2004) Pathological properties of the Parkinson's disease-associated protein DJ-1 in $\alpha$-synucleinopathies and tauopathies: relevance for multiple system atrophy and Pick's disease. Acta Neuropathol 107:489-496.

Noro R, Gemma A, Kosaihira S, Kokubo Y, Chen M, Seike M, Kataoka K, Matsuda K, Okano T, Minegishi Y, et al. (2006) Gefitinib (IRESSA) sensitive lung cancer cell lines show phosphorylation of Akt without ligand stimulation. BMC Cancer 6:277.

Overmiller AM, McGuinn KP, Roberts BJ, Cooper F, Brennan-Crispi DM, Deguchi T, Peltonen S, Wahl JK III, and Mahoney MG (2016) c-Src/Cav1-dependent activation of the EGFR by Dsg2. Oncotarget 7:37536-37555.

Perez-Nievas BG and Serrano-Pozo A (2018) Deciphering the astrocyte reaction in Alzheimer's disease. Front Aging Neurosci 10:114.

Pike CJ, Cummings BJ, Monzavi R, and Cotman CW (1994) $\beta$-amyloid-induced changes in cultured astrocytes parallel reactive astrocytosis associated with senile plaques in Alzheimer's disease. Neuroscience 63:517-531.

Qu WS, Tian DS, Guo ZB, Fang J, Zhang Q, Yu ZY, Xie MJ, Zhang HQ, Lü JG, and Wang W (2012) Inhibition of EGFR/MAPK signaling reduces microglial inflammatory response and the associated secondary damage in rats after spinal cord injury. J Neuroinflammation 9:178.

Raab G and Klagsbrun M (1997) Heparin-binding EGF-like growth factor. Biochimica Biophysica Acta 1333:F179-F199.

Roskoski R Jr. (2019) Small molecule inhibitors targeting the EGFR/ErbB family of protein-tyrosine kinases in human cancers. Pharmacol Res 139:395-411.

Saltz L, Easley C, and Kirkpatrick P (2006) Panitumumab, Nature Publishing Group, Berlin, Germany.

Sato T, Yoo S, Kong R, Sinha A, Chandramani-Shivalingappa P, Patel A, Fridrikh M, Nagano O, Masuko T, Beasley MB, et al. (2019) Epigenomic profiling discovers trans-lineage SOX2 partnerships driving tumor heterogeneity in lung squamous cell carcinoma. Cancer Res 79:6084-6100.

Schilsky RL (2010) Personalized medicine in oncology: the future is now. Nat Rev Drug Discov 9:363-366.

Schneider MR and Yarden Y (2014) Structure and function of epigen, the last EGFR ligand. Semin Cell Dev Biol 28:57-61.

Schreiber AB, Winkler ME, and Derynck R (1986) Transforming growth factor-alpha: a more potent angiogenic mediator than epidermal growth factor. Science 232 $1250-1253$.

Seroogy KB, Gall CM, Lee DC, and Kornblum HI (1995) Proliferative zones of postnatal rat brain express epidermal growth factor receptor mRNA. Brain Res 670: 157-164.

Shandra O, Winemiller AR, Heithoff BP, Munoz-Ballester C, George KK, Benko MJ, Zuidhoek IA, Besser MN, Curley DE, Edwards GF III, et al. (2019) Repetitive diffuse mild traumatic brain injury causes an atypical astrocyte response and spontaneous recurrent seizures. J Neurosci 39:1944-1963.

Sigismund S, Avanzato D, and Lanzetti L (2018) Emerging functions of the EGFR in cancer. Mol Oncol 12:3-20.

Söllvander S, Nikitidou E, Brolin R, Söderberg L, Sehlin D, Lannfelt L, and Erlandsson A (2016) Accumulation of amyloid- $\beta$ by astrocytes result in enlarged endosomes and microvesicle-induced apoptosis of neurons. Mol Neurodegener 11:38.

Spencer SA, Riley AC, Matthew A, and Di Pasqua AJ (2019) Brigatinib: novel ALK inhibitor for non-small-cell lung cancer. Ann Pharmacother 53:621-626.

Styren SD, DeKosky ST, Rogers J, and Mufson EJ (1993) Epidermal growth factor receptor expression in demented elderly: localization to vascular endothelial cells of brain, pituitary and skin. Brain Res 615:181-190.

Takeda M and Nakagawa K (2019) First- and second-generation EGFR-TKIs are all replaced to osimertinib in chemo-naive EGFR mutation-positive non-small cell lung cancer? Int J Mol Sci 20.

Tan F, Shi Y, Wang Y, Ding L, Yuan X, and Sun Y (2015) Icotinib, a selective EGF receptor tyrosine kinase inhibitor, for the treatment of non-small-cell lung cancer. Future Oncol 11:385-397.

Tan J, Li M, Zhong W, Hu C, Gu Q, and Xie Y (2017) Tyrosine kinase inhibitors show different anti-brain metastases efficacy in NSCLC: a direct comparative analysis of icotinib, gefitinib, and erlotinib in a nude mouse model. Oncotarget 8 : 98771-98781.

Tavassoly I (2015) Dynamics of Cell Fate Decision Mediated by the Interplay of Autophagy and Apoptosis in Cancer Cells: Mathematical Modeling and Experimenta Observations, Springer, Berlin, Germany.

Tavassoly I, Goldfarb J, and Iyengar R (2018) Systems biology primer: the basic methods and approaches. Essays Biochem 62:487-500.

Tavassoly I, Hu Y, Zhao S, Mariottini C, Boran A, Chen Y, Li L, Tolentino RE, Jayaraman G, Goldfarb J, et al. (2019) Genomic signatures defining responsiveness to allopurinol and combination therapy for lung cancer identified by systems therapeutics analyses. Mol Oncol 13:1725-1743.
Tavassoly I, Parmar J, Shajahan-Haq AN, Clarke R, Baumann WT, and Tyson JJ (2015) Dynamic modeling of the interaction between autophagy and apoptosis in mammalian cells. CPT Pharmacometrics Syst Pharmacol 4:263-272.

Thomas SM and Grandis JR (2004) Pharmacokinetic and pharmacodynamic properties of EGFR inhibitors under clinical investigation. Cancer Treat Rev 30:255-268.

Toyoda H, Komurasaki T, Uchida D, Takayama Y, Isobe T, Okuyama T, and Hanada K (1995) Epiregulin. A novel epidermal growth factor with mitogenic activity for rat primary hepatocytes. J Biol Chem 270:7495-7500.

Tremblay M-E, Cookson MR, and Civiero L (2019) Glial phagocytic clearance in Parkinson's disease. Mol Neurodegener 14:16.

Tripathi P, Rodriguez-Muela N, Klim JR, de Boer AS, Agrawal S, Sandoe J, Lopes CS, Ogliari KS, Williams LA, Shear M, et al. (2017) Reactive astrocytes promote ALSlike degeneration and intracellular protein aggregation in human motor neurons by disrupting autophagy through TGF- $\beta 1$. Stem Cell Reports 9:667-680.

Tyson JJ, Baumann WT, Chen C, Verdugo A, Tavassoly I, Wang Y, Weiner LM, and Clarke R (2011) Dynamic modelling of oestrogen signalling and cell fate in breast cancer cells. Nat Rev Cancer 11:523-532.

Vecchione L, Jacobs B, Normanno N, Ciardiello F, and Tejpar S (2011) EGFR-targeted therapy. Exp Cell Res 317:2765-2771.

Wakatsuki S and Araki T (2016) NADPH oxidases promote apoptosis by activating ZNRF1 ubiquitin ligase in neurons treated with an exogenously applied oxidant. Commun Integr Biol 9:e1143575.

Wakatsuki S, Furuno A, Ohshima M, and Araki T (2015) Oxidative stress-dependent phosphorylation activates ZNRF1 to induce neuronal/axonal degeneration. J Cell Biol 211:881-896.

Wang B-J, Her GM, Hu M-K, Chen Y-W, Tung Y-T, Wu P-Y, Hsu W-M, Lee H, Jin L-W, Hwang SL, et al. (2017) ErbB2 regulates autophagic flux to modulate the proteostasis of APP-CTFs in Alzheimer's disease. Proc Natl Acad Sci USA 114: E3129-E3138.

Wang L, Chiang H-C, Wu W, Liang B, Xie Z, Yao X, Ma W, Du S, and Zhong Y (2012a) Epidermal growth factor receptor is a preferred target for treating amyloid- $\beta$-induced memory loss. Proc Natl Acad Sci USA 109:16743-16748.

Wang L, Liang B, and Zhong Y (2013) Reduced EGFR level potentially mediates the A 342 -induced neuronal loss in transgenic fruit fly and mouse. Protein Cell 4: 647-649.

Wang L, Liu N, Xiong C, Xu L, Shi Y, Qiu A, Zang X, Mao H, and Zhuang S (2016) Inhibition of EGF receptor blocks the development and progression of peritoneal fibrosis. J Am Soc Nephrol 27:2631-2644.

Wang R, Zhang X, Zhang J, Fan Y, Shen Y, Hu W, and Chen Z (2012b) Oxygen-glucose deprivation induced glial scar-like change in astrocytes. PLoS One 7:e37574.

Wei H, Li D, Yang X, Shang H, Fan S, Li Y, and Song D (2016) Design and synthesis of vandetanib derivatives containing nitroimidazole groups as tyrosine kinase inhibitors in normoxia and hypoxia. Molecules 21:1693.

Wei Y, Zou Z, Becker N, Anderson M, Sumpter R, Xiao G, Kinch L, Koduru P, Christudass CS, Veltri RW, et al. (2013) EGFR-mediated Beclin 1 phosphorylation in autophagy suppression, tumor progression, and tumor chemoresistance. Cell 154: 1269-1284.

Wong E and Cuervo AM (2010) Autophagy gone awry in neurodegenerative diseases. Nat Neurosci 13:805-811.

Yang Q, Wang E-Y, Huang X-J, Qu W-S, Zhang L, Xu J-Z, Wang W, and Tian D-S (2011) Blocking epidermal growth factor receptor attenuates reactive astrogliosis through inhibiting cell cycle progression and protects against ischemic brain injury in rats. $J$ Neurochem 119:644-653.

Yang Z, Guo Q, Wang Y, Chen K, Zhang L, Cheng Z, Xu Y, Yin X, Bai Y, and Rabbie S (2016) AZD3759, a BBB-penetrating EGFR inhibitor for the treatment of EGFR mutant NSCLC with CNS metastases. Sci Transl Med 8:368ra172.

Yarden Y (2001) The EGFR family and its ligands in human cancer. signalling mechanisms and therapeutic opportunities. Eur J Cancer 37 (Suppl 4):S3-S8

Yu HA and Pao W (2013) Targeted therapies: afatinib--new therapy option for EGFRmutant lung cancer. Nat Rev Clin Oncol 10:551-552.

Yu Z, Boggon TJ, Kobayashi S, Jin C, Ma PC, Dowlati A, Kern JA, Tenen DG, and Halmos B (2007) Resistance to an irreversible epidermal growth factor receptor (EGFR) inhibitor in EGFR-mutant lung cancer reveals novel treatment strategies. Cancer Res 67:10417-10427.

Zhang S, Ju P, Tjandra E, Yeap Y, Owlanj H, and Feng Z (2016) Inhibition of epidermal growth factor receptor improves myelination and attenuates tissue damage of spinal cord injury. Cell Mol Neurobiol 36:1169-1178.

Zhang X and Neufeld AH (2005) Activation of the epidermal growth factor receptor in optic nerve astrocytes leads to early and transient induction of cyclooxygenase-2. Invest Ophthalmol Vis Sci 46:2035-2041.

Address correspondence to: Dr. Iman Tavassoly, Mount Sinai Institute for Systems Biomedicine, Icahn School of Medicine at Mount Sinai, New York, NY 10029. E-mail: iman.tavassoly@mssm.edu 